\title{
Readiness Potential in Parkinson's Disease: Effects of L-Dopa Therapy and Brain Transplants
}

\author{
D.N. Velāzquez Martīnez, F. Ostrosky-Solis, Y. Rodríguez, C. Garcīa \\ de la Cadena, R. Chayo, M.A. Guevara, M. López Cabrera and I. Madrazo \\ Depto. Psicofisiolog ía, Facultad de Psicolog ía; Depto. Farmacolog ía, Facultad de Medicine, \\ Universidad Nacional Autónoma de México y Centro Medico Siglo XXI, Mexico
}

\begin{abstract}
A fundamental question in the study of transplants to the central nervous system is the identification of the brain mechanisms that are related to the clinical improvement observed after intracerebral grafts of catecholamine producing tissue to the nigro-striatal system in some of the patients affected by Parkinson's disease (PD). The use of reliable event-related potentials may provide complementary clinical and basic information related to the graft therapeutic effects. The Vertex Readiness Potential (RP) or Bereitschaftspotential preceding self-paced voluntary movements and the Motor Potential (MP) have been reported to be modulated by noradrenergic and dopaminergic mechanisms in the brain; they were used to study pre- and postoperative changes after autoadrenal surgery.
\end{abstract}

The RP and MP preceding self-paced voluntary movements were recorded in 10 normal subjects, 15 PD patients who were candidates for surgery and $5 \mathrm{PD}$ patients who had submitted to autoadrenal transplant. Brain electrical activity was recorded using $\mathrm{Ag} / \mathrm{AgCl}$ electrodes placed at F3, F4, Fz, C3, C4, Cz and Pz, all referenced to linked mastoids. Eye movements were monitored by electrooculogram placing electrodes above and below the left lid. Brain electrical activity was amplified (bandpass $0.3-70 \mathrm{~Hz}$ ) and digitalised by a computer. Subjects were instructed to press a telegraphic key with the index finger approximately every 4 sec. Electromyographic activity (EMG) was derived from surface electrodes placed over the forearm muscle group that contracted when the key was pressed. A reverse computation program triggered from the EMG registered $1500 \mathrm{~ms}$ before to $500 \mathrm{msec}$ after the movement onset. Individual trials with excessive muscular activity or eye blinks were excluded. After an average of 80 trials, the RP and MP were identified by the criteria of Shibasaki, Shima and Kuroiwa (J Neurol 1978; 219: 15-25). Evoked potentials were recorded in normals 45 minutes after the administration of placebo or the dopaminergic agonist L-DOPA ( $250 \mathrm{mg}$ ) with $25 \mathrm{mg}$ carbidopa (Sinemet 275). The PD patients were studied with L-DOPA and after 36 hours without LDOPA both preoperatively and postoperatively (3 months after surgery). For each neuroelectric recording repeated measures ANOVAs were performed in which changes in group (Normal vs. PD), and treatment (Placebo vs. L-DOPA) were analyzed.

Without medication, differences between normal subjects and PD patients were observed in the amplitude of the RP and MP; the PD patients had lower amplitude than the normals at $\mathrm{Cz}, \mathrm{C} 3$ and $\mathrm{C} 4$. Before surgery L-DOPA produced a significant $(p<0.01)$ increase in the amplitude of the RP and MP of PD patients, but only marginal changes in normal subjects. In five patients who were registered three months after surgery we observed, without medication, a significant increase in the amplitude of the RP and $\mathrm{MP}$ at $\mathrm{Cz}$ and $\mathrm{C} 3$ and minor changes in the same direction at $\mathrm{C} 4$ and $\mathrm{Fz}$. The changes in these electrophysiological measures seem to be related to dopaminergic activity and could be helpful in evaluating some of the biochemical and electrophysiological changes after brain grafting. 

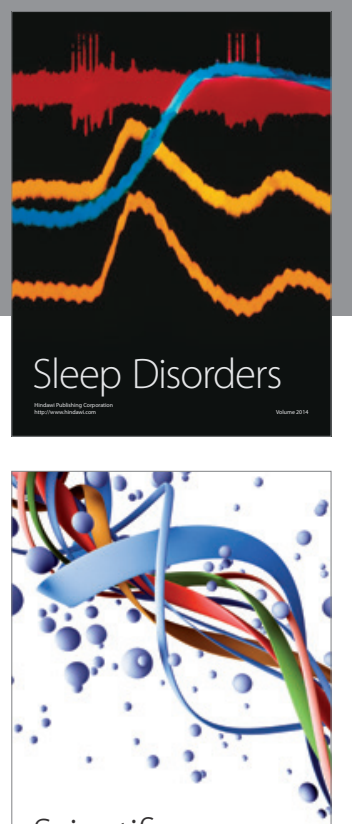

Scientifica
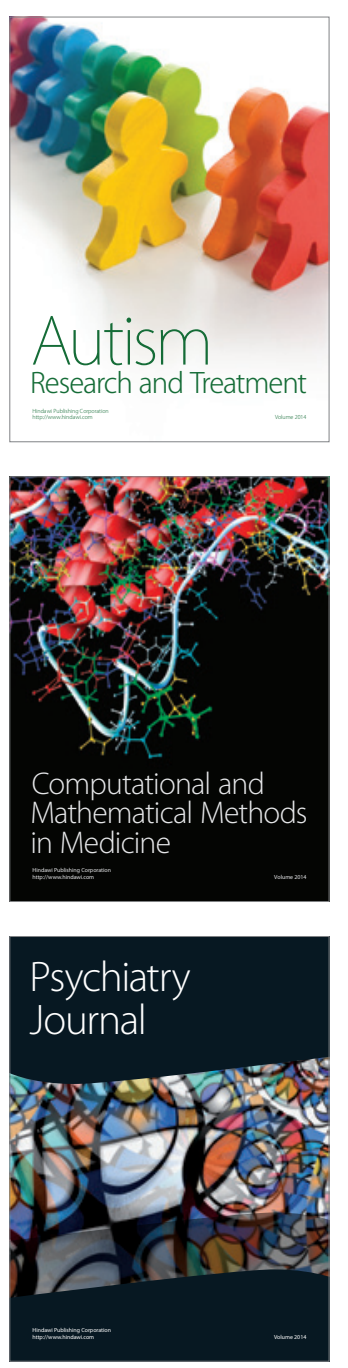
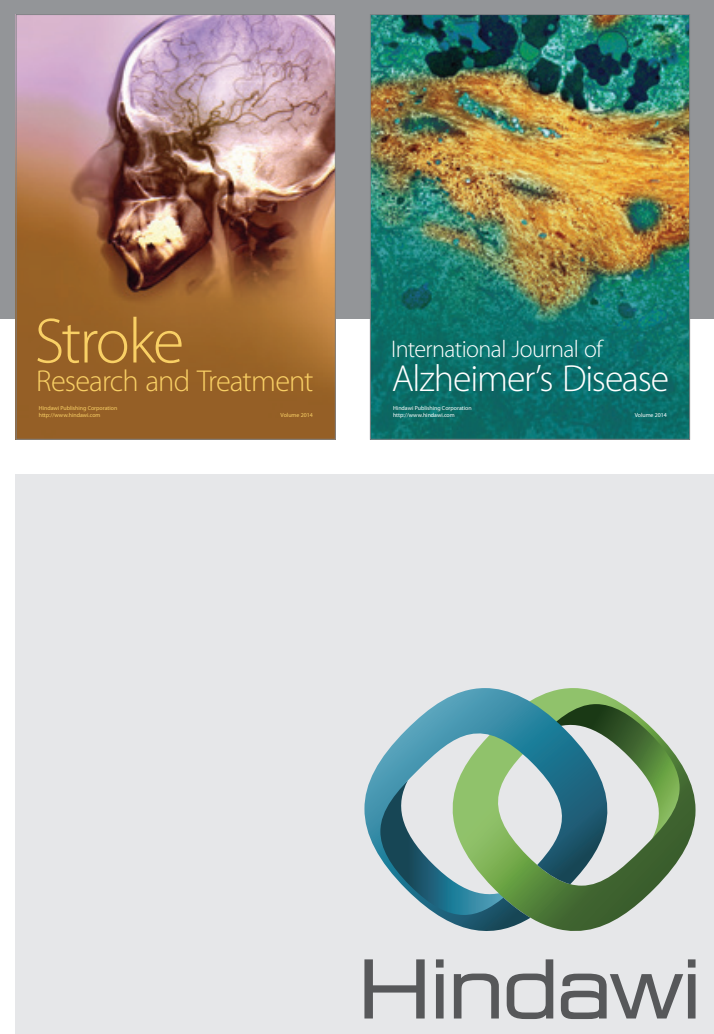

Submit your manuscripts at

http://www.hindawi.com
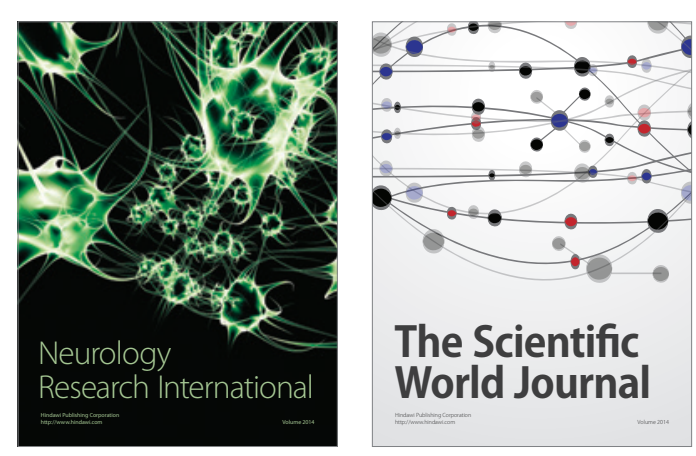

The Scientific World Journal

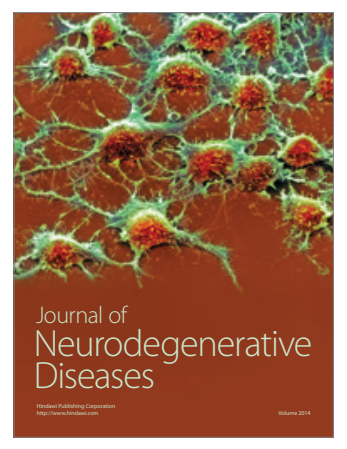

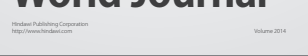

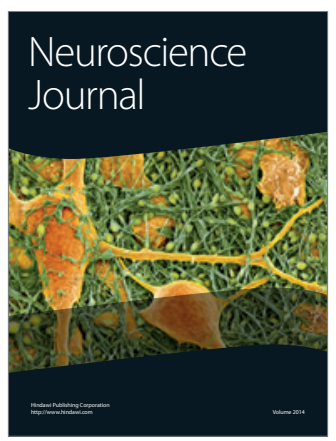

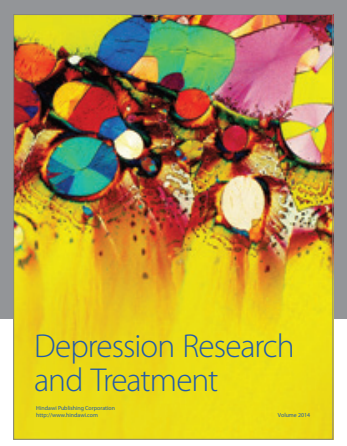
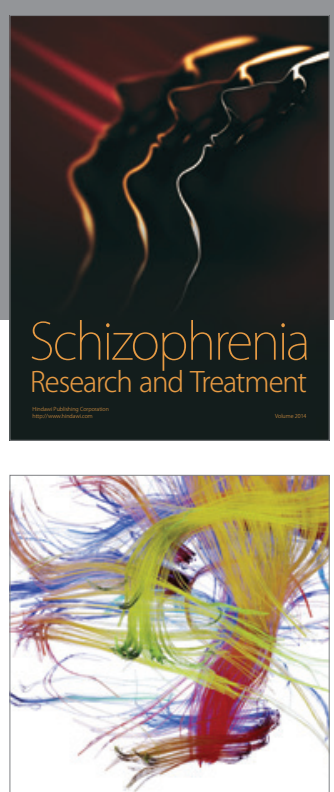

Brain Science

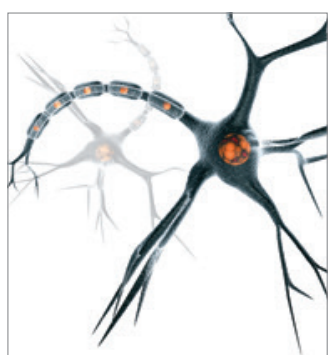

Neural Plasticity
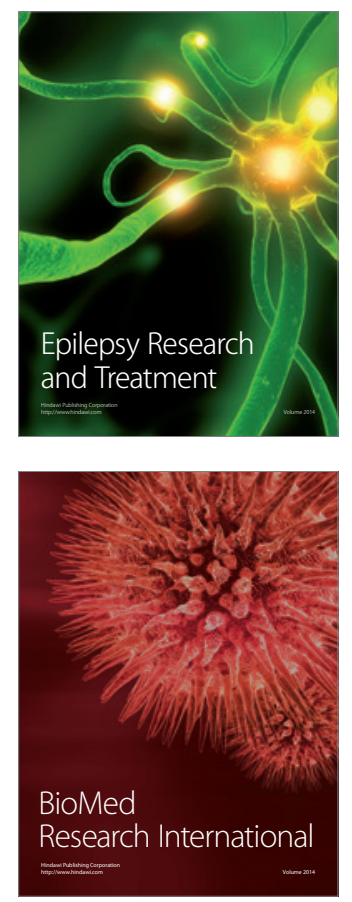

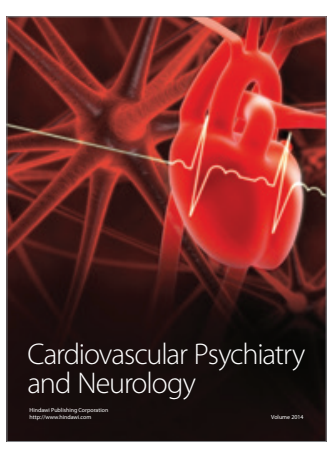

Parkinson's

Disease
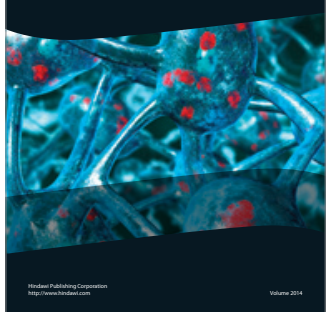